\title{
LA PUBLICIDAD SOCIAL IBEROAMERICANA EN LOS FESTIVALES CANNES LIONS Y FIAP ENTRE 2012 Y 2016
}

\author{
IBEROAMERICAN SOCIAL ADVERTISING IN CANNES LIONS \\ AND FIAP FESTIVALS BETWEEN 2012 AND 2016
}

\author{
Omar MUÑOZ-SÁNCHEZ \\ Universidad Pontificia Bolivariana \\ omar.munoz@upb.edu.co \\ Jaime Alberto OROZCO-TORO \\ Universidad Pontificia Bolivariana \\ jaime.orozco@upb.edu.co
}

Resumen: Este artículo analiza la publicidad social (PS), desde una perspectiva teórico-conceptual (términos asociados, tipos de mensajes, uso de conceptos), y desde una comparativa de los premios obtenidos en los festivales publicitarios Cannes Lions y Fiap, centrando el objeto de estudio en las propuestas de PS. En la metodología se aplica un análisis contextual analizando los países más representativos de Iberoamérica, según el Ranking The Gunn Report. Entre los resultados más relevantes se destaca que en ambos festivales Brasil está a la cabeza en cantidad de premios obtenidos. En dichos festivales las categorías preponderantes, promocional y uso creativo de los medios, contrasta con los medios tradicionales, radio y televisión, categorías poco dominantes en la obtención de galardones.

Palabras clave: Publicidad social. Marketing social. Festivales de 
publicidad. Cannes Lions. Fiap.

Abstract: This articleanalyzes the social advertising(SA), from atheoretical and conceptual perspective (associated terms, types of messages, use of concepts), and from a comparison of the awards obtained from advertising festivals such as Cannes Lions and FIAP, focusing the object of study with the proposals of SA. In the methodology, a contextual analysis is applied, analyzing the most representative Ibero-American countries, according to The Gunn Report ranking. Among the most relevant results, it is highlighted that in both festivals, Brazil is leading at the amount of awards obtained. In these festivals the preponderant categories, promotional and creative use of media, contrast with the traditional media, radio and television, less dominant categories in the obtaining of awards.

Key Words: Social advertising. Social marketing. Advertising festivals. Cannes Lions. Fiap.

\section{INTRODUCCIÓN}

La publicidad social (PS) ha venido convirtiéndose en objeto de investigación por parte de importantes teóricos, que ven en este tipo de comunicación, una alternativa a la tradicional publicidad de tipo comercial que domina el espacio de los medios de comunicación en Iberoamérica. Si bien es cierto que en América Latina han sido más evidentes los esfuerzos en materia de poner en práctica campañas de PS, por encima de los esfuerzos en su teorización, en España han sido más recurrentes los teóricos que tienen como objeto de análisis este tipo de comunicación.

En España algunos de los mayores aportes han estado a cargo de investigadores como Benet y Nos Aldás (2003), Eguizábal (2009), Alvarado (2012), Rodrigo y Rodrigo (2013), Rosario-Ubiera (2014), entre otros. Sin embargo, en el contexto latinoamericano se ha presentado un mayor esfuerzo en la implementación de campañas de PS que en su teorización, aunque en los últimos años se ha generado un incremento significativo en su desarrollo y en el establecimiento de cimientos teóricos (Alvarado, 2012). Es posible que uno de los factores obedezca a la necesidad que tienen los países en vía de desarrollo de llevar a cabo campañas de educación para 
cambiar la conducta y el comportamiento de una parte de la población.

De igual manera, se puede advertir que el uso de publicidad comercial sigue siendo el principal motor de financiación de los medios de comunicación, ya que "el grueso de la industria ha seguido trabajando mayoritariamente para causas comerciales, siendo la publicidad social escasa y relegada a una menor difusión en los grandes medios masivos por la escasez de presupuestos" (Alvarado, 2012: 199). Asimismo, en el caso español, Rodrigo y Rodrigo (2013), reconocen que "el uso de las causas sociales están siendo cada vez más utilizadas por la publicidad española y que van aumentando progresivamente las temáticas pertenecientes a más parcelas de la realidad social" (Rodrigo y Rodrigo, 2013: 253).

Como es evidente, la conjunción de cada uno de estos elementos relacionados con la PS (mayor teorización, incremento en la publicación de campañas, entre otros), ha permitido una profesionalización mayor de este sector, y como lo expone Alvarado (2012), estos elementos han permitido la creación de "agencias de publicidad especializadas en marketing y publicidad social y festivales internacionales específicos en los que se concursa; pero también bibliografía e investigaciones que abordan el tema cada vez en mayor profundidad" (Alvarado, 2012: 199).

Todos estos factores han generado que la PS tenga una mayor participación en los festivales, no solo en los especializados (El Cuartel, PubliFestival, Equidar), sino en otras premiaciones de importante alcance en los ámbitos comerciales (Cannes Lions, Fiap, El Sol, etc). Bajo esta perspectiva, se intentará "hacer un proceso investigativo que permita analizar, sintetizar, evaluar y obtener conclusiones que ayuden a construir y/o complementar la literatura existente en esta temática" (Muñoz-Sánchez y Vélez-Ochoa, 2016: 282).

\section{OBJETIVOS}

Este artículo intenta, en primera instancia, dar respuesta al siguiente objetivo principal: analizar las características que tiene la PS de los principales países Iberoamericanos y que ganaron premios en los concursos publicitarios de creatividad a nivel mundial entre los años 2012 y 2016. Se trata entonces, de contribuir en la construcción epistemológica de las teorías asociadas a la PS y de sus vínculos con el marketing social, el marketing con causa y el marketing social corporativo; además, de los 
concursos que premian la creatividad publicitaria, pero en especial, los mensajes de PS que han obtenido mayor reconocimiento.

Con base en lo anterior, se intentará dar respuesta a los siguientes objetivos específicos:

- Esclarecer los conceptos relacionados con la PS y el marketing social.

- Comparar las características de los premios obtenidos en dos de los festivales publicitarios más reconocidos internacionalmente.

- Analizar los contenidos de las campañas más exitosas de los principales países Iberoamericanos, cuyos contenidos sociales hayan sido premiados significativamente en festivales de creatividad reconocidos mundialmente.

\section{METODOLOGÍA}

Para conseguir los objetivos propuestos en esta investigación, la cual se enmarca dentro de las ciencias sociales, se optó por utilizar un enfoque mixto desde una postura pragmática. ¿Por qué pragmática? Porque como mencionan Hernández, Fernández y Baptista respecto a este tipo de estudios:

Por pragmatismo debemos entender la búsqueda de soluciones prácticas y trabajables para efectuar investigación, utilizando los criterios y diseños que son más apropiados para un planteamiento, situación y contexto en particular. Este pragmatismo implica una fuerte dosis de pluralismo, en donde se acepta que tanto el enfoque cuantitativo como cualitativo son muy útiles y fructiferos (Hernández, Fernández y Baptista, 2010: 553).

La intención de este enfoque es el de describir un fenómeno social "a partir de rasgos determinantes, según sean percibidos por los elementos mismos que están dentro de la situación estudiada" (Bernal, 2006: 57). En una primera parte, se realizó una investigación de corte cualitativo por medio de recopilación, análisis y estructuración de los aportes teóricos sobre la PS, como eje de la comunicación del marketing social, el marketing con causa y el marketing social corporativo. Este tipo de enfoque permitió 
proponer un "diseño emergente" (Valles, 2007) o particular para esta investigación, ya que como menciona Trigo:

la "investigación cualitativa es un arte" y el camino (metodología) un proceso creador. Por tanto no hay diseños previos, ni estructuras determinadas, ni formatos o modelos aplicables a todas las investigaciones. Cada investigador tiene que crear su propio camino, el camino que le permita dar respuesta a la/s pregunta/s de investigación (Trigo, 2013: 49).

En un segundo momento se realizó un análisis contextual de los concursos de creatividad publicitaria a nivel mundial y los mensajes de PS que participan en ellos. No se trató de hacer una estudio exhaustivo sobre dichos concursos, sino de comprender un fenómeno que desde una perspectiva cualitativa se entiende que "se explora el contexto estudiado para lograr las descripciones más detalladas y completas posibles de la situación con el fin de explicar la realidad "subjetiva" que subyace a las acción de los miembros de la sociedad” (Toro y Parra, 2006: 24).

En una menor proporción, pero no menos importante, se realizó un análisis de corte cuantitativo, donde se identificaron las propuestas de PS que más premios ganaron en dos de los más reconocidos festivales de publicidad a nivel Iberoamericano. Este enfoque se aborda no desde la "cuantificación de los datos cualitativos, sino al proceso no matemático de interpretación, realizado con el propósito de descubrir conceptos y relaciones en los datos brutos y luego organizarlos en un esquema explicativo teórico" (Strauss y Corbin, 2002: 12). Para lo anterior se estableció un método de análisis que aplicó procedimientos particulares que permitieron abordar el objeto de estudio desde su enunciado hasta los resultados obtenidos (Bunge, 1989).

Lo primero que se hizo fue seleccionar los festivales publicitarios de Cannes Lions (Francia) y el Festival Iberoamericano de Publicidad Fiap (Argentina). Se escogieron estos dos concursos bajos los siguientes criterios:

- Se seleccionó Cannes Lions por ser uno de los festivales más antiguos del mundo y que en 2016 registró un número record de inscripciones de piezas alcanzando la cifra de 43.101 ( $h t t p: / / g o o . g l / s Z D 3 a 8$ ). Además, este 
festival ha venido incrementando el número de categorías de acuerdo a las tendencias del sector. Por ejemplo, en 2016 se incorporaron las categorías de: Lions Innovation, Lions Health y Lions Entertainment.

- Para la selección de Fiap se tomó en cuenta que es el festival con más trayectoria en Iberoamérica ya que fue creado en 1969 en la ciudad de Rosario - Argentina. En su página de internet (www.fiapawards.com) se reconocen como el festival más importante de Iberoamérica. Al igual que Cannes Lions, Fiap incorporó seis nuevas categorías para el 2016: mejor concepto, mejor estrategia, mejor uso cultural local, idea más audaz, mensaje más innovador y premio al consumidor (único en el mundo).

Otro criterio que se tomó en cuenta fue la selección de los cinco países para analizar los premios obtenidos por la publicidad social entre 2012 y 2016. Para ello se recurrió al The Gunn Report Creative Ranking (https://www.gunnreport.com), donde se identificó que los cinco mejores países Iberoamericanos que aparecieron en el ranking mundial de 2015 fueron: Brasil puesto 4, España puesto 6, Argentina puesto 8, Colombia puesto 23 y México puesto 29. Una vez seleccionados los festivales de Cannes Lions y Fiap, así como los cinco países, se procedió a realizar una búsqueda minuciosa en las páginas de internet de los dos festivales analizando cada año (2012 hasta 2016) y cada categoría, para identificar los mensajes de PS que fueron premiados en cada uno de los países seleccionados. Una vez identificadas las campañas premiadas en cada país, se procedió a analizar la que más trofeos recibió en cada país durante los años anteriormente mencionados. Para este análisis se tomaron como base los criterios propuestos por Kotler, Hessekiel y Lee (2013), quienes ponderan la idea de tener en cuenta a los agentes de cambio, el objetivo de la campaña, los adoptantes objetivos y el impacto que se ha generado en medios de comunicación.

\section{CONTENIDO}

Las posibilidades que brinda el análisis de la PS, desde la perspectiva de sus principales teorías hasta la forma en que se ha venido posicionando como una importante forma de comunicación con los ciudadanos, ha permitido que los festivales de publicidad se vean impactados por este tipo de publicidad, en ocasiones como resultado natural de una mayor cantidad de campañas sociales y en otros momentos como la posibilidad que han 
visto las agencias de publicidad de ganar premios en festivales, lo que les relaciona con agencias creativas y exitosas.

Por tal motivo, a continuación se analizan: el marketing social (MS) como base en la construcción de la PS, el enfoque social de la comunicación publicitaria, la participación de campañas sociales en los festivales de publicidad Cannes Lions y Fiap, y finalmente, los aspectos fundamentales de las campañas ganadoras de España, Argentina, Brasil, México y Colombia, como importantes exponentes de la publicidad Iberoamericana.

\subsection{Marketing social}

El MS es la base sobre la que se han creado los postulados y la epistemología de la PS. Por tal motivo, algunos investigadores han justificado la PS como la principal herramienta de comunicación del MS (Baños y Rodríguez, 2009), o como lo plantea Gómez (2004), para quien la publicidad es el principal motor de lo que él mismo denomina el marketing hacia lo social.

Pero antes de tratar el tema de la PS es necesario entender brevemente el origen del MS y algunos de sus postulados más relevantes. En tal sentido, algunos de sus principales exponentes (Kotler y Roberto, 1992; Moliner, 1998; Leal, 2000; Pérez, 2006; Kotler, Hessekiel y Lee, 2013) han sido enfáticos en las teorías del MS y las diferencias con el marketing tradicional. Desde la concepción teórica Kotler y Roberto (1992), asumen que el MS "combina los mejores elementos de los planteamientos tradicionales de cambio social con una planificación integrada y un marco de acción, y utiliza los avances en la tecnología de las comunicaciones y las habilidades del marketing" (Kotler y Roberto, 1992: 29). Ya desde la perspectiva de la comunicación, estos mismos autores advierten que la publicidad es una forma de difusión de una causa social y la asumen como "un esfuerzo organizado, dirigido por un grupo (el agente de cambio), que intenta persuadir a otros (adoptantes objetivo) de que acepten, modifiquen, o abandonen ciertas ideas, actitudes, prácticas y conductas" (Kotler y Roberto, 1992: 7).

Desde esta perspectiva, el MS tiene muchas similitudes con el marketing tradicional, pero su real diferencia está en que el primero casi siempre involucra comportamientos, que en la mayoría de los casos son negativos o afectan una población (Pinilla, 2011). Aunque esta aseveración 
puede ser muy convincente, no se puede asegurar que el MS únicamente busca cambiar comportamientos negativos, pues en general lo que busca es el bienestar de toda la comunidad. Lo que sí es interesante dentro de las teorías del MS son: las formas en que se entienden las categorías de productos, los cambios en la mezcla de marketing y las denominaciones de los anunciantes y públicos objetivos.

Dentro de la primera concepción de MS no se piensa en categorías de productos o servicios, sino en problemas y soluciones a enfrentar, siendo las marcas las instituciones que ofrecen dichas soluciones (Alvarado, 2005). Estas mismas instituciones ya no serán catalogadas como anunciantes de productos o servicios comerciales, sino que se denominan como agentes de cambio, pues tienen como objetivo fomentar un cambio de conducta o la adopción de una idea (Orozco y Ferré, 2015); y los públicos objetivos (target) del marketing tradicional, se denominan adoptantes objetivos, pues representan aquellos "individuos, grupos, poblaciones enteras, que son el objetivo de las llamadas al cambio por parte del agente del marketing social" (Kotler y Roberto, 1992: 20).

En el caso del marketing tradicional siempre se ha trabajado la mezcla de marketing, conocida como las 4P, como la base que sustenta el desarrollo y vínculo entre las empresas con sus diferentes stakeholders (grupos de interés). En el ámbito del MS estos elementos tienen algunas diferencias que han sido estipuladas por Kotler y Roberto (1992) de la siguiente manera: el producto se vuelve intangible, al convertirse en ideas, creencias, actitudes o valores como productos sociales. El precio no será una transacción monetaria, sino el esfuerzo o el tiempo que el adoptante objetivo asume dentro del cambio social. La promoción hace referencia, al igual que el marketing tradicional, al uso de las acciones de comunicación integrada que se utilizan para difundir el concepto (publicidad, relaciones públicas, promoción de ventas, ventas personales, marketing directo). Finalmente, la plaza se entiende como el sitio en donde los adoptantes objetivo acceden a los beneficios de las campañas sociales (medios de distribución que se usan para entregar el producto social a disposición de los adoptantes objetivos).

Si bien es cierto que el MS tiene diferencias con el marketing tradicional, en donde mayores confusiones se generan es en la denominación de las acciones de las organizaciones o instituciones en torno a la acción social. En este aspecto se pueden encontrar divergencias entre el MS y 
el marketing con causa y con el marketing social corporativo (Barranco, 2005).

El marketing con causa es aquel que implementan empresas privadas que asumen una responsabilidad, considerando que no solo les interesa el crecimiento económico, sino que lleva a cabo acciones solidarias, en ocasiones de una manera altruista y en otras con miras a incrementar su imagen y reputación corporativa. Por su parte en el marketing social corporativo la empresa busca directamente generar un beneficio a una comunidad o a sus consumidores, al mismo tiempo que propende por mejorar su imagen de marca o las ventas, al conciliar la acción social con las creencias de sus consumidores. De esta forma, se puede concluir que ni el marketing con causa ni el marketing social corporativo son iguales al MS, pues en cada una de ellas los objetivos de las acciones de los agentes de cambio son diferentes.

Es claro que estas formas de MS generan beneficios a las organizaciones, pues como lo establece Muñoz (2001), las empresas que utilizan este tipo de estrategias "reciben un doble beneficio: cumplen con sus objetivos dentro de la estrategia en ventas y ganan en imagen y posicionamiento" (Muñoz, 2001: 86). Sin embargo, este no debe ser el único objetivo de las organizaciones, pues el MS social se debe implementar como vía para mejorar la calidad de vida de las personas y no solamente para beneficiarse económicamente mediante una estrategia de lavado de cara que se difunde a través de los medios de comunicación con la participación de la PS.

\subsection{Publicidad social}

La PS viene ganando un espacio cada vez más importante en diversos ámbitos, desde la cantidad de campañas publicitarias que ocupan un espacio en los medios de comunicación, así como la pertinencia de este tipo de comunicación por la gran cantidad de problemas sociales que aquejan a nuestra sociedad, e incluso, por la participación de estas campañas en los festivales de publicidad.

Aunque la PS es relativamente nueva, pues se pueden considerar sus inicios a partir de 1942 en Estados Unidos "cuando se ponen las tácticas de la publicidad al servicio de temas de utilidad pública alejados de cualquier interés mercantil" (Baños y Rodríguez, 2009: 218). Sin embargo, según 
Gumucio-Dagron (2011), el mayor desarrollo de la PS se presenta a partir de 1997 luego de reuniones de la Fundación Rockefeller en donde se discutió el papel de la comunicación en los cambios sociales del siglo que estaba por llegar. Ya para el contexto de Iberoamérica, y en especial en América Latina, se puede considerar que se vienen incrementando las campañas sociales, en algunos casos con brillantes aportaciones (Alvarado, 2012).

Desde la aparición de la PS se ha reconocido su diferencia marcada con la publicidad comercial, pues la primera toma como base las causas y proyectos sociales, además de ser generada por agentes de cambio que no tienen ánimo de lucrarse con la campañas, y sus grandes beneficiarios son el bienestar colectivo (Baños y Rodríguez, 2009). Aunque esta condición sea clara y evidente, aún existen corrientes que plantean que la PS se debe parecer a la publicidad comercial para que tenga éxito (Kotler y Roberto, 1992). Estas consideraciones sobre la comunicación de los mensajes vienen cambiando, pues incluso hay investigadores que reconocen la necesidad de separar ambos tipos de mensajes (Rosario-Ubiera, 2014), y otros que claramente entienden que no se deben mezclar ambos tipos de comunicación pues "como consecuencia de esta homogeneización, se pone de relieve su limitada capacidad para captar la atención de los públicos a los que se dirigen" (Arroyo, 2014: 206).

En otros aspectos, la PS difiere de la comercial en cuanto utiliza con mucha frecuencia una comunicación más disuasiva que persuasiva. Además, es el tipo de comunicación que mayores esfuerzos realiza en la generación de procesos de educación con los adoptantes objetivos, situación que genera amplias dificultades ya que es frecuente que los receptores de los mensajes tengan ya comportamientos muy arraigados (el esfuerzo estará centrado en la modificación de actitudes).

Finalmente, desde la perspectiva de los enfoques de la comunicación de la PS, es importante recalcar la idea que Arroyo (2014) establece al llamar la atención sobre el uso de mensajes con imágenes patéticas o de alto impacto. En alusión a esta condición el autor expone que:

Los públicos ya se han saturado de recibir mensajes de sensibilización que apelaban al catastrofismo para despertar la compasión, generando con ello un fenómeno perceptivo de fatiga de la compasión que, por un exceso de exposición al espectáculo del horror, la mayor parte de las 
veces, los espectadores solo se dedicaban a mirar imágenes del sufrimiento de los demás, sin un compromiso directo de actuación. El uso del catastrofismo solo ha servido para estimular el voyerismo de un público que se ha alimentado de una ideología basada en aceptar que el dolor solo es tolerable si son los demás los que lo sufren (Arroyo, 2014: 205).

Aunque cada vez se tiene mayor claridad sobre las formas en que la PS debe desarrollar sus estrategias de comunicación, aún se siguen encontrando algunas discrepancias sobre la forma en que se reconoce esta publicidad. Este factor se presenta, en especial, porque las empresas privadas han comenzado a realizar comunicaciones sociales con fines comerciales (Baños y Rodríguez, 2009), porque es una forma del sector privado de mostrar su solidaridad con los problemas sociales (Alvarado, 2009), y porque le han permitido a estas empresas encontrar una forma de comunicación que utiliza una retórica acorde a sus propios valores corporativos (Cano, 2015). Pero no solo se vislumbra una alta utilización de la PS por parte del sector privado por razones institucionales, sino porque "este nuevo discurso solidario está de moda, porque los ciudadanos están interesados en los valores que transmite; compran valores, votan valores y venden valores, por encima de otros intereses y consideraciones" (Rodrigo y Rodrigo, 2013: 10).

En alusión a la forma en que se dan a conocer las campañas de PS a través de sus mensajes, las consideraciones de los académicos están mucho más alineadas. Para Rodrigo y Rodrigo (2013) la creatividad en la vertiente gráfica y visual debe generar un alto impacto en la sociedad para poder generar conciencia social y valores que promuevan una conducta humana deseable. Esta condición se ha presentado en mayor porcentaje en los países latinoamericanos en donde se presenta una dualidad que pone de manifiesto la necesidad de una comunicación creativa por parte de los comunicadores y publicistas: una cantidad importante de problemáticas sociales combinado con una cantidad considerable de adoptantes objetivos de diversas condiciones culturales y sociales con los cuales comunicarse. 


\subsection{La PS Iberoamericana en los festivales Cannes Lions y Fiap}

Los concursos publicitarios tienen su origen en Estados Unidos a finales de los años 50s e inicios de los 60s. Surgieron como una forma en que los departamentos de marketing de las empresas seleccionaban sus agencias de publicidad. Además, era la forma como las agencias evidenciaban su calidad creativa frente a otras agencias de publicidad y los anunciantes:

Since then, the industry has developed several rankings systems, which judge agencies based on income figures, the overall success of an agency at award shows such as the Cannes Lions or the One Show, or a variety of individual expert evaluation (e.g., Gross Income Rankings, National Creativity Rankings, or subjective agency rankings developed by individual marketing managers of leading brands (Kübler y Propper, 2012: 60).

Esta necesidad del sector publicitario de ser reconocido por su creatividad dio origen a prestigiosos concursos como: Clio Awards en 1959, One Show en 1961, New York Festivals en 1963 y posteriormente Cannes Lions en Francia en 1969, el cual nació del ya existente festival de 1954 que premiaba la publicidad exclusivamente en cinemas y que se celebraba de manera alterna entre las ciudades Venecia en Italia y Cannes en Francia. Si bien el concurso nace en 1954, sólo hasta 1969 se crearon los premios bajo la denominación de: oro, plata y bronce, y en 1984 definió como sede permanente a la ciudad francesa.

Con la creación de estos concursos también surgieron investigaciones sobre el tema. Fue así como Reid, Lane, Wenthe y Smith (1985) y Beltramini y Blasko (1986) estudiaron cómo funcionaban los premios de publicidad; Pendleton (1988) analizó cómo y porqué las agencias de publicidad pagaban elevados costos por participar en los festivales; Schweitzer y Hester (1992) se interesaron por la importancia de la posición que ocupaban las agencias en los concursos de publicidad; Buzzell (1964), El-Murad y West (2003), Goldenberg, Mazursky y Solomon (1999) y Kover (1995) investigaron sobre la importancia que tenía la creatividad para lograr una efectividad publicitaria duradera para las marcas. Aunque otros autores 
no consideran evidente que los concursos de creatividad influyeran en la decisión de los departamentos de marketing, si parece existir un interés por parte de las agencias de publicidad por usar los concursos como indicador para aumentar su liderazgo y reputación (Merino y Repiso, 2016, p. 56), o como una manera de exhibir su excelencia creativa: "non of the early advertising agency literatura directly mentions that winning awards affects agency selention; though the result of winning awards might be used as an indication of an agency's creativity" (Polonsky y Waller, 1995: 28).

Estos concursos creativos favorecieron que redactores publicitarios, diseñadores y directores de arte encontraran la oportunidad de alimentar su carrera profesional al considerar que: "creative people (copywriters and art directors) believe that creativity is necessary for effectiveness" (Kover, Goldberg y James, 1995: 29), o como la posibilidad de alimentar sus currículos, debido a que los concursos "are widely perceived as indicator of advertising performance, with a strong emphasis on creative excellence" (Helgesen, 1994: 43). Aunque en muchas ocasiones redactores y directores de arte tengan percepciones diferentes de la creatividad, Young (2000).

En los últimos años se ha visto un cambio importante no sólo en la incorporación de nuevas categorías, como en el caso de Cannes Lions (cyber, mobile, innovation, health, integrated y data) debido a la evolución de los medios y la forma de comunicar los mensajes, sino también por necesidad de premiar la efectividad creativa, lo que ha llevado a que los "Senior agency executives were selected to assess their own campaigns in terms of originality and strategy, and were also queried about whether those campaigns would win creativity, and effectiveness, awards" (Kilgour, Sasser y Scott, 2013: 163) Lo anterior puede tener explicación en las palabras de Rodrigo y Rodrigo (2013) cuando afirman que la creatividad es "la herramienta que nos permite innovar, emprender nuevos retos, atreverse con nuevas ideas, usar la imaginación para crear y reinventarse para hacer posibles nuevas formas de ser, de pensar, de actuar y de comunicar las causas sociales" (Rodrigo y Rodrigo, 2013: 256). Estas últimas palabras que mencionan los investigadores, son las que nos mueven a indagar sobre los premios de creatividad y su relación con los mensajes de PS. Se trata de una apertura mental donde el concepto de creatividad "debe abordarse desde una perspectiva interdisciplinar”. (Muñoz-Sánchez, 2017: 267) Tal vez porque como mencionan nuevamente Rodrigo y Rodrigo (2013): 
Las conductas prosociales y el altruismo se constituyen en un tema central en los distintos tipos de comunicación. La solidaridad y todas sus manifestaciones se ponen de moda, es una tendencia muy común en la actualidad. Los valores solidarios y los comportamientos altruistas han entrado de lleno y de forma explícita en los escenarios políticos, empresariales y publicitarios y están condicionando de forma directa y clara los mensajes comunicativos (Rodrigo y Rodrigo, 2013: 256).

Estas conductas prosociales que están de moda pueden conducir a que las agencias realicen acciones publicitarias sólo para participar en los concursos con el único objetivo de ganar premios, sin que sean el resultado de un plan serio de marketing desde donde se plantean unos objetivos y se definen unas estrategias. Quizá, porque como mencionan Koslow, Sasser y Riordan (2003) "Understanding why some advertisements are more creative than others is vital, but a fundamental and frustrating limitation is that perception of creativity differ depending on whom one ask" (Koslow, Sasser y Riordan, 2003: 96). De esta manera se puede determinar que la PS se manifiesta como una forma de comunicación que responde a un cambio social, dicho cambio se fundamenta en la transformación de la sociedad para mejorar las condiciones de vida de sus miembros. De ser así, cobra relevancia conocer qué impacto tiene la PS en los concursos de creatividad, el tipo de temáticas que más se ha premiado en los últimos años, pero especialmente, si este tipo de mensajes realmente son reconocidos por la comunidad publicitaria, los agentes de cambio y los adoptantes objetivos.

Para lo anterior, se recolectó información que permitiera comparar la proporción de premios obtenidos por mensajes de PS en los concursos de Fiap (Tabla 1) y Cannes Lions (Tabla 2), frente a la totalidad de premios obtenidos entre los años de 2012 y 2016. 
Tabla 1.

Comparativo total de premios versus premios recibidos por PS en Fiap entre los años 2012 y 2016

\begin{tabular}{|c|c|c|c|c|c|c|c|c|c|c|}
\hline \multirow[b]{2}{*}{ Mro } & \multicolumn{2}{|c|}{ Brasil } & \multicolumn{2}{|c|}{ Argentina } & \multicolumn{2}{|c|}{ Expeñas } & \multicolumn{2}{|c|}{ Colombia } & \multicolumn{2}{|c|}{ Nérios } \\
\hline & $\begin{array}{l}\text { Prarrice } \\
\text { totsic; }\end{array}$ & $\begin{array}{c}\text { Premixe } \\
\text { PS }\end{array}$ & $\begin{array}{l}\text { Prenios } \\
\text { totales }\end{array}$ & $\begin{array}{c}\text { Premise } \\
\text { PS }\end{array}$ & $\begin{array}{l}\text { Premiss } \\
\text { totalss }\end{array}$ & $\begin{array}{c}\text { Premias } \\
\text { PS }\end{array}$ & $\begin{array}{l}\text { Pretios } \\
\text { totales }\end{array}$ & $\begin{array}{c}\text { Prenios } \\
\text { PS }\end{array}$ & $\begin{array}{l}\text { Premios } \\
\text { :otalss }\end{array}$ & $\begin{array}{c}\text { Premiog } \\
\text { FS }\end{array}$ \\
\hline 2016 & 55 & 7 & 16 & 2 & 57 & 13 & 18 & 7 & 6 & 0 \\
\hline 2015 & 112 & 15 & 28 & 2 & 80 & 23 & 27 & 13 & 17 & 3 \\
\hline 2014 & 113 & 33 & 41 & 6 & 56 & 11 & 32 & 5 & 10 & 1 \\
\hline 2013 & 105 & 13 & 34 & 3 & 34 & 4 & 15 & 4 & B & 1 \\
\hline 2012 & 44 & 3 & 35 & 0 & 33 & 3 & 38 & 10 & 34 & 0 \\
\hline Tow & 429 & 71 & 174 & 13 & 260 & 54 & 130 & 40 & 75 & 5 \\
\hline के & & 15.556 & & 6,75 & & $20,76 \%$ & & $30.76 \%$ & & $6,66 \%$ \\
\hline
\end{tabular}

Fuente: elaboración propia a partir de la página de Internet de Fiap

(http://www.fiapawards.com)

Tabla 2.

Comparativo total de premios versus premios recibidos por PS en Cannes Lions entre los años 2012 y 2016

\begin{tabular}{|c|c|c|c|c|c|c|c|c|c|c|}
\hline \multirow[b]{2}{*}{ דrio } & \multicolumn{2}{|c|}{ Erasil } & \multicolumn{2}{|c|}{ Arçentina } & \multicolumn{2}{|c|}{ Espara } & \multicolumn{2}{|c|}{ Colombla } & \multicolumn{2}{|c|}{ Méxiloo } \\
\hline & $\begin{array}{l}\text { Framins } \\
\text { totales }\end{array}$ & $\begin{array}{c}\text { Prorica } \\
\text { p5 }\end{array}$ & $\begin{array}{l}\text { Prerica } \\
\text { :otales }\end{array}$ & $\begin{array}{c}\text { Tremice } \\
\text { PS }\end{array}$ & $\begin{array}{l}\text { Promios } \\
\text { totales }\end{array}$ & $\begin{array}{c}\text { Premias } \\
\text { PS }\end{array}$ & $\begin{array}{c}\text { Fremias } \\
\text { totales }\end{array}$ & $\begin{array}{c}\text { Premias } \\
\text { P5 }\end{array}$ & $\begin{array}{l}\text { Premias } \\
\text { totales }\end{array}$ & $\begin{array}{c}\text { Premia: } \\
\text { P5 }\end{array}$ \\
\hline 20.6 & 92 & 23 & 40 & 17 & 27 & 5 & 12 & 9 & 18 & 5 \\
\hline 2015 & $1 C B$ & 23 & 26 & 11 & 48 & 22 & 19 & 9 & 27 & 6 \\
\hline 2014 & 107 & 23 & 34 & 9 & 37 & 14 & 13 & 10 & 20 & 7 \\
\hline 2013 & 115 & 25 & 26 & 9 & 22 & 5 & 7 & 3 & 12 & 2 \\
\hline 2012 & 79 & 4 & 27 & 7 & 18 & 2 & 16 & 11 & 17 & 5 \\
\hline Tota & 501 & 100 & 153 & 53 & 152 & 48 & 69 & 42 & 24 & 25 \\
\hline 8 & & 19,4643 & & 34,648 & & $31,57 \%$ & & $60,86 \%$ & & 26,596 \\
\hline
\end{tabular}

Fuente: elaboración propia a partir de la página de internet de Cannes Lions (https://www.canneslions.com/winners_awards/release_of_awards/)

Con los resultados obtenidos se puede observar que Brasil es el país que mayor número de premios ha recibido en ambos concursos, tanto a nivel general como por la temática de PS, sin embargo, Colombia se presenta como el que proporcionalmente más premios ha recibido por este tipo de temáticas. En Fiap por ejemplo, el 30,76\% y en Cannes Lions el $60,86 \%$ de los premios obtenidos están relacionadas con temáticas como: el conflicto armado que vive el país desde hace varias décadas, medioambiente, discapacidad psicomotriz, salud pública, etcétera. Por 
otra parte, cabe destacar el cambio significativo que se presentó en el año 2012 donde países como Brasil, Argentina y España que tradicionalmente obtienen un volumen importante de premios en general, recibieron pocos premios en ambos concursos por la temática de PS. El caso de Colombia en el año 2012, donde recibió 10 y 11 premios en ambos festivales, se explica por un caso puntual, se trató de la campaña denominada "Ríos de Luz (Rivers of Lights)" la cual estaba dirigida a motivar a la desmovilización de guerrilleros para que regresaran a sus hogares en época de navidad. Esta acción de PS recibió 4 y 6 premios en Fiap y Cannes Lions respectivamente, convirtiéndose históricamente en una de las campañas más premiadas para el país. Lo interesante es que propuestas posteriores como: "Operación Belén" (2013) o "Eres mi Hijo" (2014), que también fueron realizadas para el Ejército Nacional de Colombia, han sido consistentes en su estructura de comunicación, logrando repetir premios en estos mismo concursos.

Por otra parte, al analizar las cuatro categorías más premiadas en Fiap (Tabla 3) y Cannes Lions (Tabla 4), se puede encontrar que en Fiap categorías como: Medios, Interactivo, Prensa, Promocional y Efectividad Creativa alcanzan el 58,99\% de los trofeos tomando como referencia que se premian 13 categorías. De igual manera, en Cannes Lions las cuatro categorías más premiadas son Direct, Outdoor, PR y Promo, congregando el $47 \%$ de las 24 categorías.

Tabla 3.

Premios de PS obtenidos por categorías en Fiap entre los años 2012 y

\begin{tabular}{|c|c|c|c|c|c|c|c|}
\hline Categoría & Brasil & Argentina & España & Colombia & México & Total & $\%$ \\
\hline Televisión & 3 & - & 1 & - & - & 4 & 2,18 \\
\hline Gráfica & 4 & - & 1 & 7 & 1 & 13 & 7,10 \\
\hline Vía Pública & 6 & - & 2 & 3 & - & 11 & 6,01 \\
\hline Radio & - & 1 & - & 6 & - & 7 & 3,82 \\
\hline Medios & 15 & - & 14 & 4 & 2 & 35 & 19,12 \\
\hline Interactivo & 6 & 2 & 9 & 3 & - & 20 & 10,92 \\
\hline Técnica de Prod. Audiov. & 1 & 2 & 2 & 2 & - & 7 & 3,8 \\
\hline Diseño & 2 & - & 6 & - & - & 8 & 4,37 \\
\hline Promocional & 9 & 4 & 11 & 6 & 1 & 31 & 16,93 \\
\hline Prensa & 14 & 2 & 4 & 2 & - & 22 & 12,02 \\
\hline Integral & 2 & - & - & 4 & - & 6 & 3,27 \\
\hline Efectividad Creativa & 9 & 2 & 4 & 3 & 1 & 19 & 10,38 \\
\hline Redes & - & - & - & - & - & - & 0 \\
\hline Total & 71 & 13 & 54 & 40 & 5 & 183 & 100 \\
\hline
\end{tabular}

Fuente: elaborado por los autores a partir de la página de internet de FIAP

(http://www.fiapawards.com) 
Tabla 4.

Premios de PS obtenidos por categorías en Cannes Lions entre los años 2012 y 2016

\begin{tabular}{|c|c|c|c|c|c|c|c|}
\hline Categoría & Brasil & Argentina & España & Colombia & México & Total & $\%$ \\
\hline Branded Content & 4 & - & 3 & 1 & - & 8 & 2,98 \\
\hline Creative Data Lions & 3 & - & - & - & 1 & 4 & 1,49 \\
\hline Creative Effectiveness & 7 & - & - & - & - & 7 & 2,61 \\
\hline Cyber Lions & 10 & 2 & 6 & - & 1 & 19 & 7,08 \\
\hline Design Lions & 4 & - & 3 & 1 & - & 8 & 2,98 \\
\hline Digital Craft Lions & - & - & - & - & - & - & 0 \\
\hline Direct Lions & 7 & 6 & 10 & 4 & - & 27 & 10,07 \\
\hline Entertainment Lions & - & - & - & - & - & - & 0 \\
\hline Entertainment for Music & - & - & - & - & - & - & 0 \\
\hline Film Lions & - & 11 & - & - & 1 & 12 & 4,47 \\
\hline Glass & - & - & - & - & - & - & 0 \\
\hline Health \& Wellness Lions & 6 & 5 & - & 2 & - & 13 & 4,85 \\
\hline Innovation Lions & - & $=$ & - & - & - & - & 0 \\
\hline Integrated Lions & - & - & - & - & - & - & 0 \\
\hline Media Lions & 10 & 4 & 4 & 2 & 2 & 22 & 8,2 \\
\hline Mobile Lions & 7 & 2 & 1 & 2 & 2 & 14 & 5,22 \\
\hline Outdoor Lions & 8 & 5 & 6 & 4 & 3 & 26 & 9,7 \\
\hline Pharma Lions & 2 & $=$ & 1 & 2 & 1 & 6 & 2,23 \\
\hline PR Lions & 10 & 5 & 4 & 10 & 3 & 32 & 11,94 \\
\hline Print \& Publishing Lions & 7 & 4 & 5 & 2 & 2 & 20 & 7,46 \\
\hline Product Design Lions & - & - & - & 2 & - & 2 & 0,7 \\
\hline Promo \& Activation Lions & 13 & 8 & 4 & 7 & 9 & 41 & 15,29 \\
\hline Radio Lions & 2 & 1 & 1 & 2 & - & 6 & 2,23 \\
\hline Titanium Lions & - & - & - & 1 & - & 1 & 0,37 \\
\hline Total & 100 & 53 & 48 & 42 & 25 & 268 & 100 \\
\hline
\end{tabular}

Fuente: elaborado por los autores a partir de la página de internet de Cannes Lions (https://www.canneslions.com/winners_awards/release_of_awards/)

Cuando se observan los premios obtenidos en Cannes Lions se evidencia una mayor cantidad de premios de PS recibidos por la mayoría de países, a diferencia de España con respecto a los recibidos en Fiap. En el caso de Brasil, por ejemplo, se presenta un incremento del 3,12\%; Argentina también presenta un aumento del $11.53 \%$; España por su parte muestra una ligera disminución de 1,45\%; Colombia se mantiene casi estable con tan sólo un $1 \%$ de incremento de premios en Cannes Lions frente a Fiap, y México es el país que presenta una mayor diferencia, logrando un $11,84 \%$.

Entendiendo el panorama de la PS en los concursos publicitarios de Fiap y Cannes Lions, se encontró que las propuestas que más premios recibieron en cada país en los últimos 5 años fueron (Tabla 5): 
Tabla 5.

Mensajes de PS más premiadas en cada país entre los años 2012 y

2016

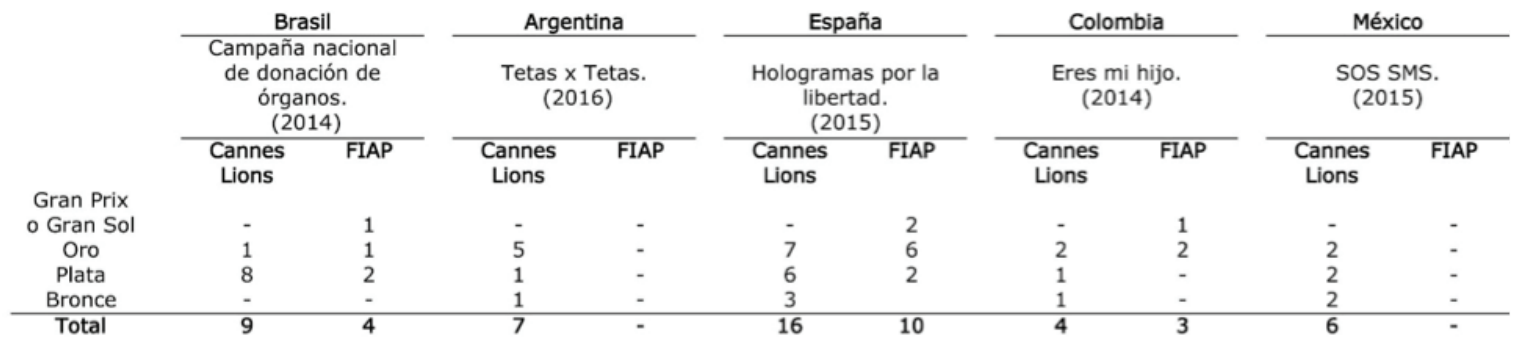

Fuente: elaborado por los autores.

El mensaje de PS más premiado de los cinco países entre los años 2012 y 2016 fue la campaña "Hologramas por la libertad" realizada en España en el año 2015. Esta campaña recibió 26 premios en ambos concursos, lo que la convierte en un referente importante en esta temática. Le sigue la "Campaña Nacional de Donación de Órganos de Brasil (ABTO)" la cual aparece referenciada en los concursos como "Bentley Burial- ABTO", esta campaña recibió 13 premios en ambos concursos. En tercer lugar aparecen "Tetas x tetas" de Argentina y "Eres mi hijo" de Colombia ambas con 7 premios. Finalmente se ubica México con "SOS por MSM" con 6 premios. Tanto Argentina como México no registran premios obtenidos en Fiap.

\section{Fiap}

\subsection{Análisis de campañas ganadoras de PS en Cannes Lions y}

Las campañas de PS ganadoras de premios en los festivales de Cannes Lions y Fiap tienen en común algunos aspectos que es importante advertir. En todos los casos se analizan campañas que han sido puestas en marcha por agentes de cambio (anunciantes) representados por asociaciones, fundaciones o instituciones sin ánimo de lucro, lo que representa una acción de PS, alejada de la comunicación utilizada por marcas privadas (marketing con causa o marketing social corporativo). En cada campaña se tocan problemáticas de alto impacto en Iberoamérica, según las necesidades de los ciudadanos de cada país. Además, las 
repercusiones no solo han sido en la obtención de los premios en festivales, sino en un importante impacto en todo tipo de medios, generando de esta forma un efecto mediático inmediato, lo anterior si se toma en cuenta que como menciona "la mitología de la publicidad es una dimensión estudiada como discurso alegórico, que bajo vibrantes formas expresivas encierra un mensaje cifrado, una enseñanza sobre el ser humano y sobre lo que le trasciende" (Gil, 2016: 616).

A continuación se realizará una breve descripción de las campañas ganadoras de los festivales Cannes Lions y Fiap más importantes de cada uno de los cinco países con mayor cantidad de premios, y que tradicionalmente han estado a la cabeza en cuanto a la publicidad en Iberoamérica: Argentina, Brasil, Colombia, España y México. Los elementos que se tendrán en cuenta para el análisis corresponde a los recomendados por Kotler, Hessekiel y Lee (2013), en este caso nos referimos al agente de cambio, los objetivos de la campaña, los adoptantes objetivos, y finalmente, el impacto que ha generado en medios.

\subsubsection{Campaña "Tetas $x$ Tetas” (Argentina)}

La campaña que ha tomado como nombre Tetas por Tetas, fue lanzada en Argentina en el 2016, como parte de la propuesta de concientización sobre los problemas que ocasiona el cáncer de mama (www.macma.org. ar). Uno de los aspectos interesantes de la campaña surge de la idea de utilizar la censura llevada a cabo en la red social Instagram en donde no se permitía postear imágenes de mujeres que mostraran sus pezones. Esta censura provocó igualmente una campaña en diversas redes sociales, la cual se conoció como \#freethenipple. Basados en esta condición, el uso de un hombre con sobrepeso, permitió hacer el autoexamen como si se tratase de una mujer, y por ende esquivando las posibilidades de ser censurado en medios de comunicación. 
Gráfico 1.

Campaña "Tetas x tetas"

\section{moeme \#mRnBOOBS4BOOBS}

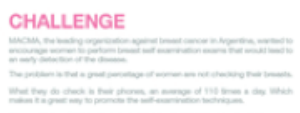

IDEA

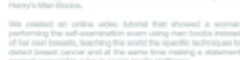

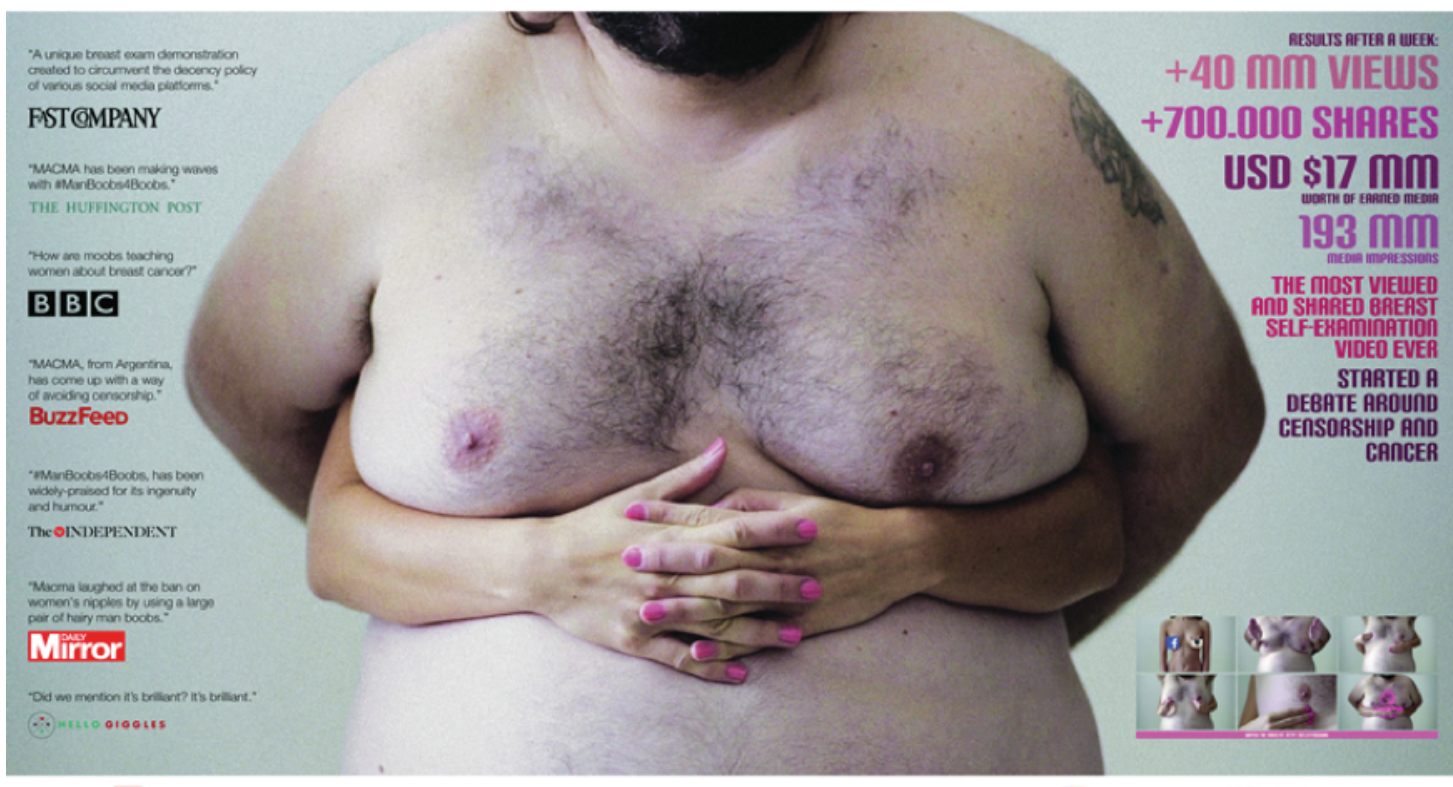

Fuente: https://goo.gl/WzX2vg.

- Agente de cambio. El agente de cambio que firma la campaña "Tetas x Tetas" ha sido el movimiento ayuda cáncer de mama (MACMA). Esta Asociación sin ánimo de lucro fue fundada en 1997 en Buenos Aires (Argentina), y está constituida por mujeres que tuvieron cáncer de mama. Dentro de sus funciones está orientar y acompañar a las mujeres que sufren la enfermedad al igual que a sus familias, así, sus mayores esfuerzos se encaminan a la detección temprana, más que en la prevención. Además, tienen el apoyo del Instituto Nacional de Cáncer de Argentina, la Unión Latinoamericana Contra el Cáncer en la Mujer y de otras organizaciones a nivel internacional.

- Objetivos. La campaña cuenta con dos objetivos claramente identificados por su agente de cambio. Por un lado se pretende alertar a las 
mujeres y sus familias sobre el problema de padecer cáncer de mama, y en segundo lugar, busca comunicar de manera directa y sin censura, la forma más adecuada en que las mujeres pueden examinar sus senos de manera natural.

- Adoptante objetivo. Claramente el público al que se dirige la campaña son las mujeres que pueden llegar a sufrir de cáncer de mama, al igual que sus familiares. Como se ha mencionado, la comunicación tiene como objetivo la detección temprana de la enfermedad, con lo cual las adoptantes objetivo pueden ser amplios segmentos de población en donde incluso no se discrimina por estatus socioeconómico, nivel de estudios, u otra condición.

- Impacto en medios. Aunque la campaña ha sido difundida principalmente en redes sociales, los efectos en medios masivos de comunicación han generado una amplia cobertura. Los principales medios argentinos han hecho eco de la campaña. Periódicos como El Clarín (Argentina), El Periódico y El País (España), El Nuevo Herald (Estados Unidos), entre otros, han incluido en sus ediciones online comentarios de alabanza por la idea de esta acción comunicativa. Por ejemplo, El Clarín reveló que "en total, el video llegó a más de 8,5 millones de personas. Fueron tantas, que tuvieron que traducirlo al inglés. El perfil de Facebook de MACMA ganó 20.000 seguidores" (https://goo.gl/Wh3kGy).

\subsubsection{Campaña "Hologramas por la libertad” (España)}

La campaña "hologramas por la libertad" ha sido lanzada por una plataforma ciudadana llamada "No somos delito", la cual está formada por alrededor 100 organizaciones de la sociedad civil (www.nosomosdelito.net). La campaña surge luego de la creación en España en marzo de 2015, de lo que se conoce como la "ley mordaza", la cual prohíbe que los ciudadanos se manifiesten en frente del congreso de los diputados, ni organizar asambleas en espacios públicos ni participar en una manifestación, sin que antes se tenga que realizar un aviso a las autoridades competentes. Esta ley es vista como una limitante a los derechos de expresión, por lo cual se crea una manifestación pública virtual a partir de la creación de hologramas que marchaban frente a instituciones públicas en España. 


\section{Gráfico 2.}

\section{Campaña "Hologramas por la libertad"}

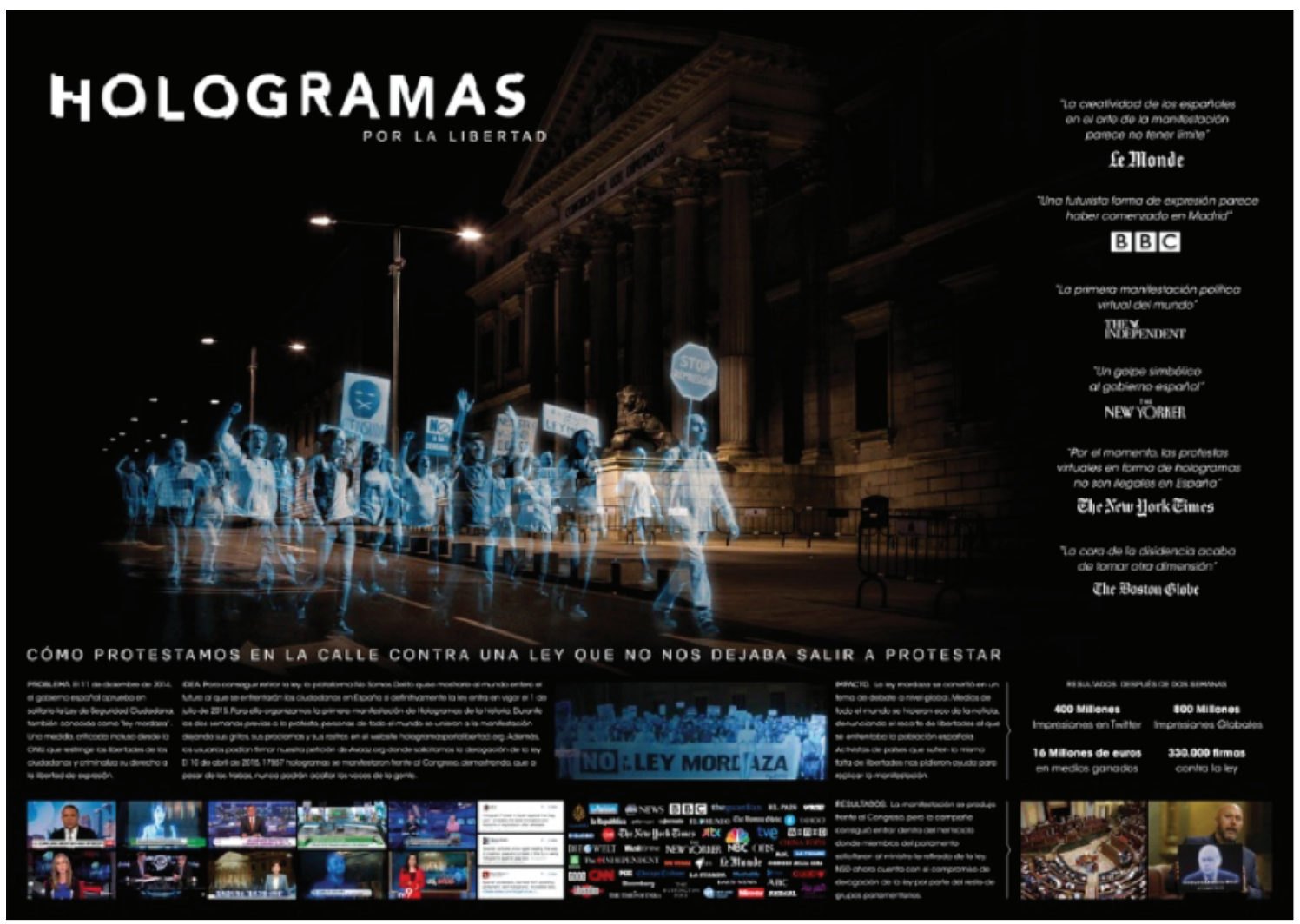

Fuente: https://goo.gl/kLW2lo.

- Agente de cambio. La plataforma "No somos delito" que actúa contra la reforma del código penal, la ley de seguridad ciudadana y la ley de seguridad privada en España. Ellos mismos se autodenominan como personas que sueñan con una sociedad solidaria, empática, consciente que puede unirse, como en este caso a través de los hologramas y arengas como "Les da igual que vivas en la calle, pero no quieren que te expreses en la calle".

- Objetivos. La intención de la campaña es denunciar la llamada "ley mordaza", y que miles de personas puedan movilizarse a través de los hologramas, pero que además, se genere conciencia de las injusticias que 
comenten al aprobar este tipo de leyes. En términos de los creadores de la campaña, se trata de "Una protesta multitudinaria a través de la que demostraremos, que a pesar de las trabas, no podrán acallar nuestras voces $\mathrm{y}$ que, aunque tengamos que convertirnos en hologramas, seguiremos protestando" (www.hologramasporlalibertad.org).

- Adoptante objetivo. Uno de los aspectos más interesantes, a parte de la gran novedad de la creación de la primera "protesta virtual" por medio del uso de hologramas, es que esta campaña tiene varios grupos de stakeholders a los que se dirigen. En este aspecto, los adoptantes objetivo se concretan tanto en las personas que brindan su información real para convertirse en hologramas, a los ciudadanos para que conozcan los efectos de la "ley mordaza" y tomen acciones en su contra, además de los políticos que tienen a su cargo la aprobación de la ley, y finalmente, los medios de comunicación sobre los que se ha generado una gran repercusión que ha sido utilizado para la viralización de los objetivos de esta iniciativa.

- Impacto en medios. Las repercusiones en medios masivos de comunicación ha sido uno de los aspectos más relevantes de la campaña, pues a la viralidad en internet se le suma la difusión masiva que ha logrado en todo el mundo, principalmente en periódicos y noticieros. Algunos de los comentarios más favorables sobre la campaña han sido emitidos por medios como el periódico El Mundo, quienes expresan que "Euronews, CNN, BBC, The Boston Globe, The New Yorker, Bloomberg fueron algunos de los muchos medios de comunicación que cubrieron 'la primera marcha con hologramas del mundo' [...] La protesta tuvo una audiencia global de 800 millones de personas y 400 millones de impresiones en redes sociales, que abrieron el debate mundial sobre la libertad de expresión" (https://goo.gl/jlMLoe).

\subsubsection{Campaña "Eres mi hijo” (Colombia)}

Colombia viene realizando grandes campañas de PS que tienen diferentes frentes de trabajo (por la variedad de problemáticas) y con diversos agentes de cambio (organizaciones públicas, sociedad civil, ONG, entre otros). Este panorama ha hecho que el país reciba una cantidad importante de premios en los últimos años. La campaña "Eres mi hijo", emitida en el año 2013, ha sido una de las más valoradas en los festivales, luego que ya lo hiciera "Ríos de luz", ambas enfocadas en la 
desmovilización de guerrilleros que se encuentran en las selvas haciendo parte principalmente de las FARC y del ELN. Como hecho digno de mención "Ríos de luz" recibió el primer oro en categoría Titanium en la historia de la publicidad colombiana.

"Eres mi hijo" hace un llamado desde la voz de las madres de guerrilleros que se encuentran haciendo parte de las filas de las FARC, para que regresen a su familia, con una comunicación emotiva con frases como: "te quiero junto a mí, no solo tu foto junto a mí, abrazarte, recuperarte". Al final de cada uno de los mensajes aparece un copy a manera de colofón que expresa: "antes de ser guerrillero, eres mi hijo. Esta navidad te espero en casa".

\section{Gráfico 3.}

\section{Campaña "Eres mi hijo"}

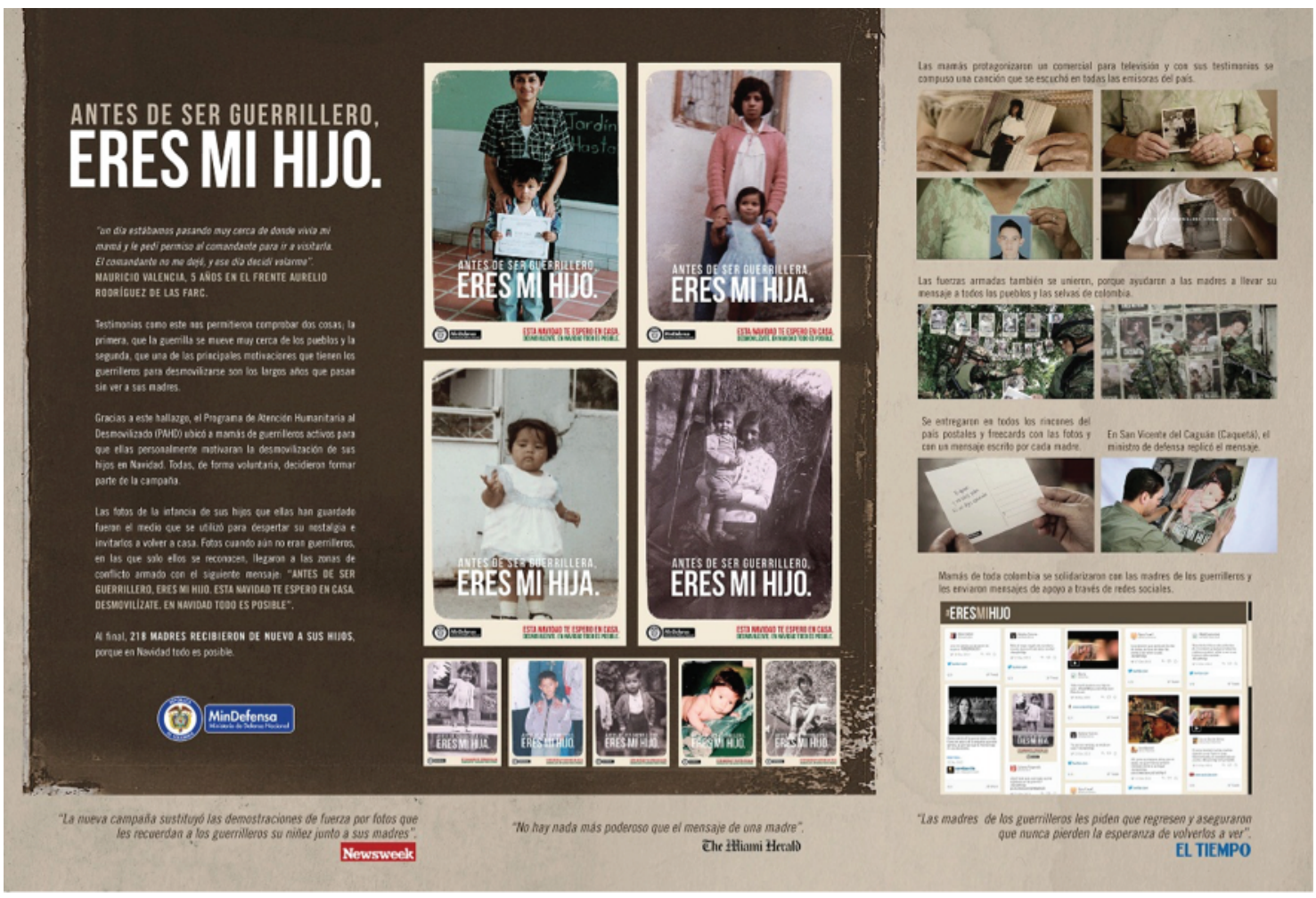

Fuente: https://goo.gl/MvJ973 
- Agente de cambio. Tanto en la campaña "Ríos de luz" como en "Eres mi hijo" el agente de cambio ha sido el Ministerio de Defensa Nacional de la República de Colombia a través del Programa de Atención Humanitaria al Desmovilizado (PAHD). Este Ministerio viene realizando grandes campañas de PS, en las que han incluido una importante mezcla de medios, pues al uso de los medios tradicionales (ATL), ha sumado una serie de acciones en medios BTL.

- Objetivos. Los objetivos de la campaña están enfocados en la desmovilización de guerrilleros de las Fuerzas Armadas Revolucionarias de Colombia (FARC) principalmente, y del Ejército de Liberación Nacional (ELN), en segundo lugar.

- Adoptante objetivo. Aunque ambos grupos al margen de la ley (FARC y ELN) tienen guerrilleros en sus filas, la mayoría de las campañas que se han emitido en Colombia, con relación a la desmovilización, han tenido como adoptantes objetivo a los guerrilleros de las FARC. Además, es importante recalcar que en un alto porcentaje, los guerrilleros son campesinos, personas con un grado de escolaridad muy bajo y que en muchas ocasiones han sido reclutados de manera forzosa.

- Impacto en medios. Las referencias a la campaña "Eres mi hijo" se han difundido en una gran variedad de medios, al igual que se ha evidenciado en las campañas analizadas anteriormente. En este aspecto, los efectos de esta acción de comunicación se pueden materializar en las desmovilizaciones producidas por los guerrilleros, pero además, en la forma en que esta campaña ha alcanzado reconocimiento nacional e internacional. En el periódico El Espectador, uno de los más influyentes medios del país, se menciona que estas acciones son una "publicidad por la paz", y que "Con esa estrategia aumentó un 30\% el número de reinsertados en los últimos años" (https://goo.gl/wQvsM0).

\subsubsection{Campaña nacional de donación de órganos (Brasil)}

Una de las acciones de PS más exitosas de Iberoamérica de los últimos años ha sido la campaña nacional de donación de órganos que se realizó en Brasil en el 2013. Una fuerte e impactante comunicación de expectativa se realizó mediante el uso de una noticia de un magnate brasileño, quien en un programa de televisión anunció que iba a enterrar 
en el jardín de sus mansión uno de sus autos más costosos. Esta noticia produjo comentarios muy variados en el país, hasta que el día del suceso, el magnate acompañado de una gran cantidad de medios de comunicación, anunció que no lo haría, pero que todos los días los seres humanos nos enterraban con nuestros órganos, mucho más valiosos que un auto lujoso. Con este suceso se dio inicio a la campaña nacional de donación de órganos en Brasil.

\section{Gráfico 4.}

Campaña "Donación de órganos"

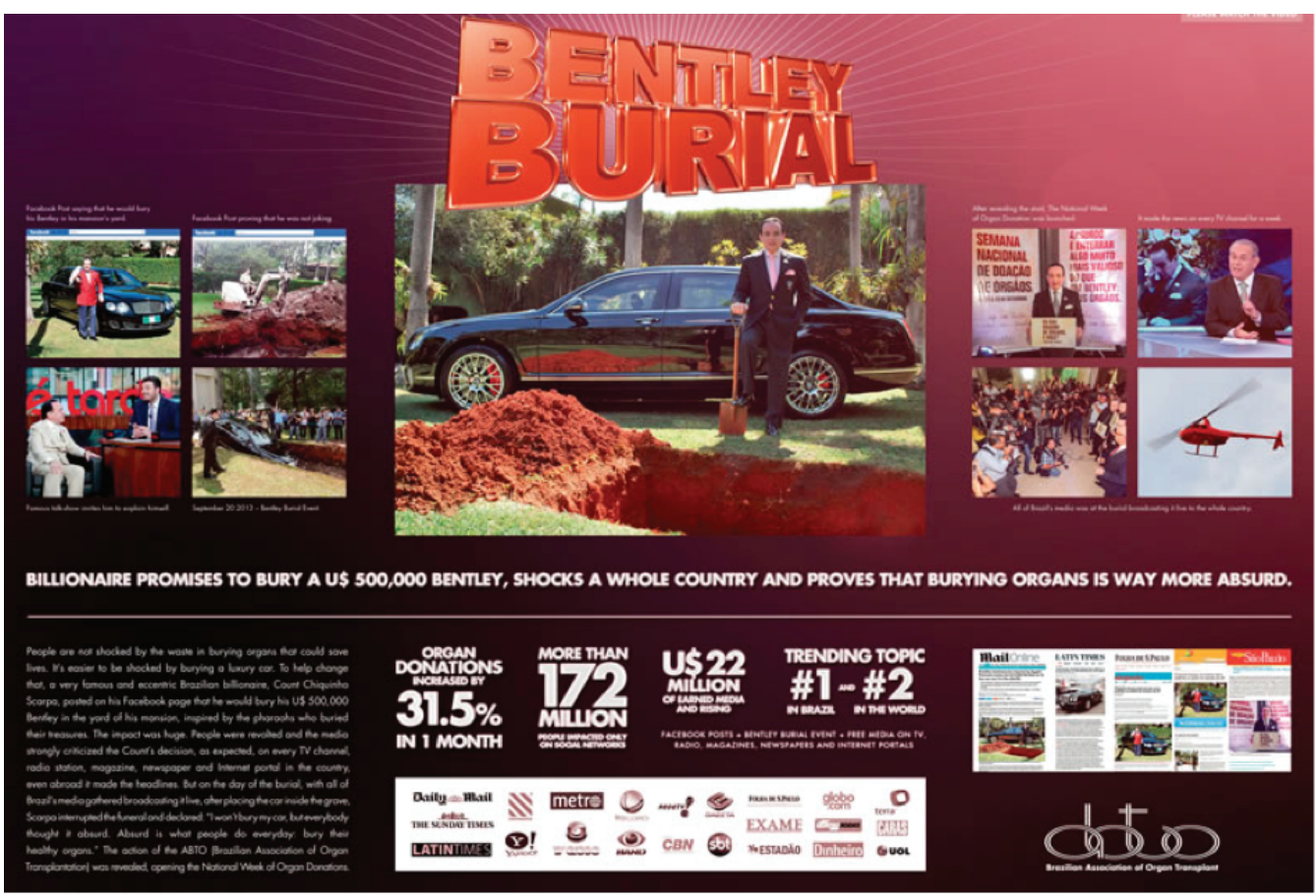

Fuente: https://goo.gl/7nyZ9k

- Agente de cambio. Quien firma esta original campaña es la Asociación Brasileña de Trasplantes de Órganos (ABTO), en conjunto con el Sistema Nacional de Trasplantes del Ministerio de Salud de Brasil.

- Objetivos. La doble finalidad de la campaña se explica mediante la idea de concientizar a las personas de la sociedad brasileña de lo valiosos 
que pueden ser los órganos para una persona que está a la espera de un trasplante, y de igual manera, de la solicitud expresa para que las personas de cualquier índole se conviertan en donadores.

- Adoptante objetivo. Cualquier persona que tenga contacto con la campaña se convierte en un adoptante objetivo, pues la comunicación no solo estaba dirigida a personas que fuesen posibles donantes, sino a sus familiares.

- Impacto en medios. Dos momentos diferentes hicieron que la campaña tuviera el impacto esperado en medios. Por un lado, el efecto generado por el magnate que anuncia el entierro de su auto, y en segundo instante por el desenlace hacia la campaña de donación de órganos. Una forma de corroborar el impacto, no solo mediático, sino de la donación de órganos, es mediante esta noticia de la página web del Festival El Ojo de Iberoamérica: "la cobertura de las 300 notas que hizo tanto la prensa local como la internacional y el incremento en el $31 \%$ en las donaciones de órganos fueron argumentos más que suficientes para que ganara el máximo galardón" (https://goo.gl/Zk5EkS).

\subsubsection{Campaña "SOS SMS” Cruz Roja (México)}

El desarrollo de la campaña "SOS SMS" inició en el 2015 con la idea de que cualquier persona que tenga un teléfono móvil ingrese una información básica de su condición física general, enfermedades, alergias, etc., de tal manera que en caso de emergencia una persona pueda en su teléfono digitar *SOS y dicha información llegará en mensaje de texto, lo que permitiría al personal encargado de atender al paciente conocer más sobre datos de salud vitales en el momento que se enfrente a una emergencia. 


\section{Gráfico 5. \\ Campaña "SOS SMS"}

CRUZ ROJA MEXICANA

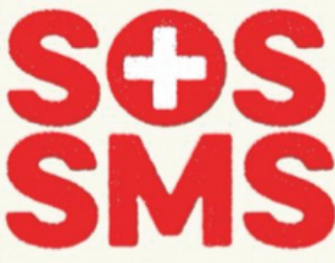

We turned people's mobile phone into a life saving tool.

Everyday, the Mexican Red Cross attends more than 3,000 emergencies.

of the cases people die for not

作 who are in a state of shock or unconscious

But there's something we all have at hand. Our mobile.

We created an online emergency service accessible from the victim's mobile, no matter what model or operating system matter what model or operating system save their fives.
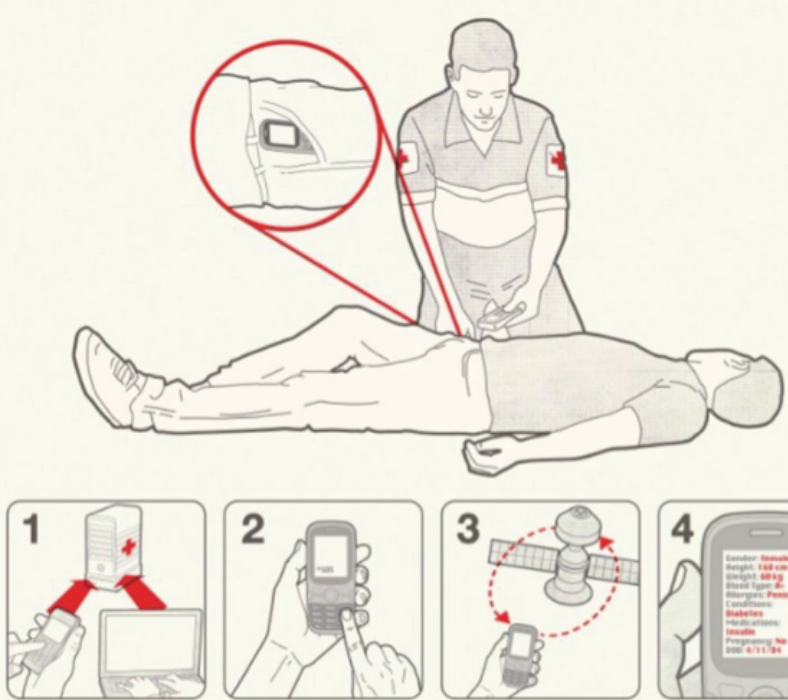

People join the database by replying an SMS or via web. They uploard basic medical hiomation increding blood medcations, height, weight,
gender, and pregnancy.

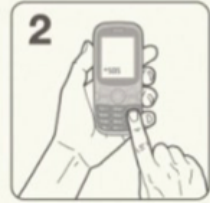

Red Cross rescuers dial $\star$ SOS from the victim's mobile phone. cocess is granted even from
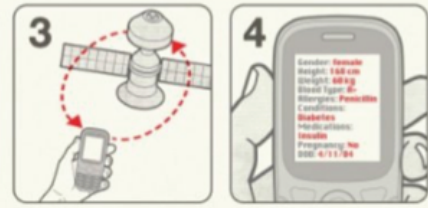

A message is sent back to the mobile is displayed on screen. phone.

if contains the data associated with that phone number. Thus, rescouers save valuable that can help save the victimy

Fuente: https://goo.gl/L8dd0w

- Agente de cambio. La Cruz Roja mexicana es la organización que está al frente de esta campaña como agente de cambio. En este caso, los adoptantes objetivos ingresan a la página web de la Cruz Roja mexicana e ingresan su información médica para que pueda ser utilizada en caso de una emergencia.

- Objetivos. El objetivo primario de la campaña ha sido que los mexicanos ingresen al sitio web de la Cruz Roja y que ingresen la información esencial de su condición física, pero esto lleva al objetivo final de la campaña que es salvar la vida de las personas que sufren un accidente, y que por falta de información por parte de los paramédicos no pueden realizar su trabajo de manera totalmente eficaz.

- Adoptante objetivo. Mexicanos de cualquier condición, que sean 
portadores de un teléfono móvil, sin importar si cuenta con condiciones de salud que deban ser comunicadas o no a un paramédico al momento de un accidente.

- Impacto en medios. Tanto medios de comunicación mexicanos como internacionales hicieron eco de la noticia. Los medios especializados en publicidad y marketing han difundido la noticia, pero además, por su pertinencia e importancia para lo comunidad, ha sido compartida por medios masivos y por redes sociales. En uno de estos medios se rescata además los resultados de la campaña, en donde se expone que "un total de 300 mil usuarios fueron invitados a través de un SMS. Hasta el momento, el 40 por ciento ha registrado correctamente su información médica personal en la base de datos de la Cruz Roja" (https://goo.gl/TCFyhO).

\section{CONCLUSIONES}

Las conclusiones que emergen de esta investigación sobre la PS de Iberoamérica en los festivales Cannes Lions y Fiap, pueden ser amplias $\mathrm{y}$ variadas dado que se trata de un tema que viene cobrando mayor importancia, en parte por la participación de la PS en los más importantes festivales, sino por la relevancia que esta comunicación genera en una mejorar la calidad de vida de los ciudadanos.

Si bien es una realidad que en América Latina se han incrementado los estudios y teorías sobre PS (Alvarado, 2012), aún se requiere el desarrollo de teorías propias y de avances investigativos que permitan una epistemología propia. En el caso de España, se evidencia un incremento significativo en las campañas de PS en los medios de comunicación (Rodrigo y Rodrigo, 2013), especialmente en los años 2014 y 2015. El año 2016 no fue tan significativo para España en materia de premios de PS, si bien disminuyó sólo 1,45\%, fue Cannes Lions 2016 el año menos afortunado disminuyendo en 17 la cantidad de premios recibidos respecto a los años 2014 y 2015. Con Fiap 2016 ocurrió lo mismo, disminuyó en 10 la cantidad de premios respectos a los dos años anteriores.

Colombia se presenta como el país con más potencial de desarrollo de PS. Si bien es el país que proporcionalmente recibe más premios en materia de PS, aún no logra alcanzar el protagonismo en cuanto a cantidad de premios que han alcanzado España, Argentina y Brasil. Debido a la complejidad de problemas sociales que vive este país, es claro que las 
agencias de publicidad y los agentes de cambio (instituciones públicas y privadas), han encontrado aquí una oportunidad de destacar en los concursos internacionales de publicidad.

México es otro país que va aumentando su protagonismo en este tipo de concursos, aunque pareciera que tienen una mayor intención de figurar en Cannes Lions debido a que presenta una marcada diferencia en la cantidad de premios recibidos, un total de 25 , frente a los 5 obtenidos en Fiap durante los años 2012 y 2016.

Desde el ámbito netamente teórico, se puede concebir que el MS guarda diferencias conceptuales con el marketing tradicional, en especial en la concepción de aspectos como: la noción del público objetivo del marketing tradicional se trabaja como adoptantes objetivos, y los anunciantes son considerados como agentes de cambio, como ejes fundamentales. Igualmente, desde la perspectiva de los tipos de MS, se establecen diferencias con el marketing con causa (enfocado en las acciones filantrópicas de la empresa), y el marketing social corporativo (que busca tanto un beneficio a la comunidad como a sus propios intereses, en especial en la mejora de su imagen y reputación corporativa).

Otra de las conclusiones importantes que sobresale dentro de la proyección teórica, apunta a la idea de que la función principal de la PS es cambiar actitudes de los adoptantes objetivo, fundamentado en procesos de comunicación disuasiva (corregir conductas), por encima de la comunicación persuasiva del marketing tradicional, que busca principalmente inducir a sus públicos objetivos a la compra de un bien o de un servicio.

Brasil, Argentina, España, Colombia y México muestran una tendencia a participar cada vez más en festivales publicitarios con propuestas de temáticas relacionadas con la PS. Cannes Lions al contar con más variedad de categorías facilita que este tipo de propuestas encuentren un espacio apropiado donde puedan concursar y exponer sus temáticas. A diferencia de Fiap, Cannes Lions cuenta con 11 categorías más y entre las que han comenzado a ganar reconocimiento: Cyber Lions, Mobile Lions, Media Lions, Health \& Wellness Lions y Creative Data Lions.

Las campañas que han sido analizadas dentro de este artículo, corresponden a las que mayores premios han obtenido en los festivales Cannes Lions y Fiap, pero además de un importante reconocimiento por parte de la ciudadanía y de los medios de comunicación. Cada una de 
estas campañas revelan fehacientemente las necesidades de la comunidad Iberoamericana, pues en ellas se evidencian problemas de salud pública, de violación de derechos como la libertad de expresión, o la problemática ocasionada por los grupos guerrilleros, en el caso particular de Colombia.

Asimismo, en el establecimiento de los mensajes se evidencia una mezcla interesante de propuestas creativas, pues se palpa una comunicación muy emotiva (Eres mi hijo de Colombia), una campaña con un enfoque jocoso y divertido (Tetas $\mathrm{x}$ tetas de Argentina), un manejo mucho más racional y directo (Hologramas por la libertad de España), una campaña de expectativa con una buena resolución que capta la atención (Campaña nacional de donación de órganos de Brasil), y finalmente una propuesta de involucramiento de los adoptantes objetivo con sus dispositivos móviles (SOS SMS de México).

Dadas las grandes problemáticas que aquejan a los países Iberoamericanos, en especial a los de América Latina, se hace indispensable que tanto agentes de cambio, como agencias de publicidad, le sigan apuntando a la creación y divulgación de campañas de PS, pues no sólo han hecho que la publicidad iberoamericana se destaque, sino que además, permite continuar con el mejoramiento de las condiciones de vida de los ciudadanos de nuestros países.

Finalmente, las líneas de investigación futuras que se desprenden de esta investigación pueden estar enmarcadas en el conocimiento de los tipos de campañas de PS que se implementan en cada uno de los países Iberoamericanos y en especial indagando sobre la incidencia de estas acciones comunicativas en la generación de capacidades en las poblaciones en las que se desarrolla su área de confluencia. Además, es importante reconocer los avances teóricos que sobre la PS se lleva a cabo en Iberoamérica, pues es pertinente la creación de teorías propias dadas las diversas condiciones de nuestros países y de sus poblaciones. 


\section{REFERENCIAS BIBLIOGRÁFICAS}

ALVARADO, M. (2005). "La Publicidad Social: concepto, objeto y objetivos". Revista de estudios para el desarrollo social de la comunicación 2, 265-284.

(2009). “Publicidad Social? Usos y abusos de lo social en la publicidad". Revista Icono 14, 13, 125-151.

(2012). "La publicidad en el marco de la comunicación para el desarrollo: hacia un nuevo modelo de publicidad para el cambio social”. Cuadernos de Información y Comunicación 17, 191-207.

ARROYO, I. (2014). "Publicidad social eficaz desde la universidad: los aspectos experimentales". Zer 19 (37), 191-211.

BAÑOS, M. y RODRÍGUEZ, T. (2009). "Desarrollo de un modelo de predicción de la eficacia para la publicidad social”. Revista Icono $14,13,214-238$.

BARRANCO, F. (2005). Marketing social corporativo. La acción social de la empresa. Madrid: ESIC.

BELTRAMINI, R. F. y VINCENT, J. B. (1986). "An Analysis of AwardWinning Advertising Headlines". Journal of Advertising research 26 (2). 47-52

BENET, V. y NOS ALDÁS, E. (2003). La publicidad en el tercer sector. Barcelona: Icaria.

BERNAL, C. (2006). Metodología de la investigación. México: Pearson Education.

BUNGE, M. (1989). La investigación científica. Barcelona: Ariel.

BUZZELL, R. (1964). "Predicting short-term changes in market share as a function of advertising strategy". Journal of Marketing Research 8, 27-31.

CANNES LIONS AWARDS. http://goo.gl/sZD3a8 [11/08/2016].

CANO, L. (2015). El uso de las figuras literarias en el discurso publicitario. Análisis de los recursos retóricos en la publicidad social. Trabajo fin de máster. Universidad Jaume I, Departamento de Ciencias de la Comunicación.

EGUIZÁBAL, R. (2009). Industrias de la conciencia, una historia social de la publicidad en España. Barcelona: Península.

EL ESPECTADOR. "Publicidad por la paz". http://www.elespectador. com/entretenimiento/unchatcon/publicidad-paz-articulo-468633 
[08/09/2016].

EL MUNDO. "Hologramas por la libertad". http://www.elmundo.com. ve/firmas/fabiana-culshaw/hologramas-por-la-libertad.aspx [08/09/2016].

EL-MURAD, J. y WEST, D. (2004). "The definition and measurement of creativity: What do we know?". Journal of Advertising Research 44, 188-201.

EL OJO DE IBEROAMÉRICA. "Un entierro glorioso de Leo Burnett Tailor Made". http://www.elojodeiberoamerica.com/un-entierroglorioso-de-leo-burnett-tailor-made/ [09/09/2016].

FIAP AWARDS. http://www.fiapawards.com/articulo. php? sec $=$ articulo \&lan $=e s \& i d=77$ [19/08/2016].

GIL, S. (2016). "Estudio de caso publicitario: el empoderamiento de las divinidades femininas y "la diosa que hay en ti". Signa. Revista de la Asociación Española de Semiótica 25, 609-630 (también en: http:// revistas.uned.es/index.php/signa/article/view/16939/14525).

GOLDENBERG, J.; MAZURSKY, D. \& SOLOMON, S. (1999). "The fundamental templates of quality ads". Marketing Science 18 (3), $333-351$.

GÓMEZ, J. (2004). "Mercadeo con causa social ¿Responsabilidad social o estrategia comercial?". Revista Economía, Gestión y Desarrollo 2, 123-147.

GUMUCIO-DAGRON, A. (2011). "Comunicación para el cambio social: clave del desarrollo participativo”. Signo y Pensamiento 30 (58), 26-39.

HELGESEN, T. (1994). "Advertising award and advertising agency performance criteria". Journal of Advertising Research 34(4), 43-43.

HERNÁNDEZ, R.; FERNÁNDEZ, C. y BAPTISTA, P. (2010). Metodología de la investigación. México D.F.: McGraw-Hill.

HOLOGRAMAS POR LA LIBERTAD. http://www.hologramasporlalibertad.org/\#home [08/09/2016].

KILGOUR, M.; SASSER S. \& SCOTT K. (2013). "Creativity Awards: Great Expectations?". Creativity Research Journal 25 (2), 163171.

KOSLOW, S.; SASSER, S. \& RIORDAN, E. (2003). "What is Creative to Who and Why? Perceptions in Advertising Agencies". Journal of Advertising Research 43 (1), 96-110. 
KOTLER, P. \& ROBERTO, E. (1992). Marketing social: estrategias para cambiar la conducta pública. México: Díaz de Santos.

KOTLER, P.; HESSEKIEL, D. \& LEE, N. (2013). Lo bueno funciona. Bogotá: LID.

KOVER, A. (1995). “Copywriters' Implicit Theories of Communication: An Exploration". Journal of Consumer Research 21 (3), 596-611.

KOVER, A.; GOLDBERG, S. M. \& JAMES, W. (1995). "Creativity vs. Effectiveness? An Integrating Classification for Advertising". Journal of Advertising Research 35 (6), 29-40.

KÜBLER, R. \& PROPPER, D. (2012). "Faking or Convincing: Why Do Some Advertising Campaigns Win Creativity Awards?". Bur Business Research 5 (1), 60-81.

LEAL, A. (2000). Gestión del Marketing Social. Madrid: McGraw-Hill.

MERCA2.0. "SOS SMS, de Grey México la única campaña mexicana dentro del shortlist de Mobile". http://www.merca20.com/sos-smsde-grey-mexico-la-unica-campana-mexicana-dentro-del-shortlistde-mobile/ [08/09/2016].

MERINO, A. y REPISO, R. (2016). "Las agencias colombianas de publicidad como agentes del marketing nacional e internacional". Anagramas 14 (28), 51-66.

MOLINER, M. (1998). Marketing Social, la gestión de las causas sociales. Madrid: ESIC.

MOVIMIENTO AYUDA CÁNCER DE MAMA. http://www.macma.org. ar/ [07/09/2016].

MUÑOZ, Y. (2001). El mercadeo social en Colombia. Medellín: Editorial Universidad EAFIT.

MUÑOZ-SÁNCHEZ, O. (2017). La planificación de cuentas. Una investigación del concepto de estrategia desde su origen hasta las agencias de publicidad en Colombia. Medellín: Universidad Pontificia Bolivariana.

MUÑOZ-SÁNCHEZ, O. y VÉLEZ-OCHOA, C. I. (2016). Aproximación al estado del arte de la planificación de cuentas en Colombia. En Tendencias publicitarias en Iberoamérica. Diálogo de Saberes $y$ experiencias, I. Zacipa-Infante et alii. Alicante: Editorial Universitas.

NO SOMOS DELITO. http://www.nosomosdelito.net/ [07/09/2016].

OROZCO-TORO, J. y FERRÉ, C. (2015). "La difusión de las causas 
sociales y su impacto en la percepción de la imagen de marca. El caso español de Televisió de Catalunya”. Cuadernos.info 1 (36), $125-138$.

PENDLETON, J. (1988). “Awards”. Advertising Age 59 (1), 94.

PÉREZ, L. (2006). Marketing social, teoría y práctica. México: Prentice Hall.

PINILLA, M. (2011). Contribución del marketing social a la sostenibilidad de fundaciones sin ánimo de lucro: un estudio de caso. Tesis de maestría, Universidad Nacional de Colombia. Disponible en: http://www.bdigital.unal.edu.co/3534/1/maricelapinillapena.2011. $p d f[09 / 09 / 2016]$.

POLONSKY, M. \& WALTER, D. (1995). "Does winning advertising awards pay?: the australian experience". Journal of Advertising Research 35 (1), 25-36.

REID, L.; REID, R.; WENTHE, L. \& SMITH, O. (1985). "Creative strategies in highly creative domestic and international television advertising”. International Journal of Advertising 4 (1), 11-18.

RODRIGO, I. y RODRIGO, L. (2013). "La causa social en la creatividad publicitaria: Valores y confianza. Los discursos publicitarios en situaciones de crisis". Pensar la Publicidad 7 (2), 253-274.

ROSARIO-UBIERA, R. (2014). "Publicidad solidaria: eficacia de la publicidad televisiva de manos unidas". Prisma Social 13, 610651.

SCHWEITZER, J. C. \& HESTER, J. B. (1992). "The importance of winning advertising award shows". Southwestern Mass Communication 7 (1), 55-66.

STRAUSS, A. y CORBIN, J. (2002). Bases de la investigación cualitativa. Técnicas y procedimientos para desarrollar la teoría fundamentada. Medellín: Ed. Universidad de Antioquia.

THE GUNN REPORT. The most awarded Countries \& Agencies in the world. https://www.gunnreport.com [20/09/2016].

TORO, I. y PARRA, R. (2006). Método y conocimiento. Metodología de la investigación. Medellín: Universidad EAFIT.

TRIGO, E. (2013). "Fundamentos ontológicos, epistemológicos y metodológicos en la investigación cualitativa". En Procesos creativos en investigación cualitativa, Trigo, Gil \& Pazos, volumen 1. Colombia: Léeme. 
VALLES, M. (2007). Técnicas cualitativas de investigación social. Reflexión metodológica y práctica profesional. Madrid: Síntesis. YOUNG, Ch. (2000). "Creative Differences between Copywriters and Art Directors". Journal of Advertising Research 40 (3), 19-26.

Recibido el 10 de febrero de 2017. Aceptado el 15 de marzo de 2017. 